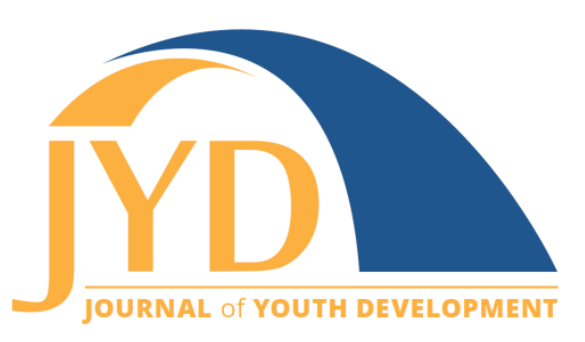

http://jyd.pitt.edu/ | Vol. 16 Issue 4 DOI 10.5195/jyd.2021.1145 | ISSN 2325-4017 (online)

\title{
Book Review: Handbook of Positive Youth Development: Advancing Research, Policy, and Practice in Global Contexts
}

\section{Barbara Thelamour}

Swarthmore College

bthelam1@swarthmore.edu

\begin{abstract}
The Handbook of Positive Youth Development: Advancing Research, Policy, and Practice in Global Contexts (2021) edited by Radosveta Dimitrova and Nora Wiium, provides an expansive addition to the literature on Positive Youth Development. It offers stakeholders across disciplinary boundaries cuttingedge frameworks and critical takeaways that will deeply inform research and practice efforts with adolescents. This review provides an overview of the major parts of the edited volume, highlighting specific key chapters and providing suggestions for future directions.
\end{abstract}

Key words: positive youth development, book review, global research, adolescence

As scholars have decried, much of the study of human thought and behavior emphasizes what goes wrong (Baumeister et al., 2001; Paolini \& McIntyre, 2019), and the developmental stage that tends to bear the brunt of this negativity bias is adolescence. Adolescent delinquency, deviant peer norms, and risky behaviors have dominated the empirical literature on this developmental stage, painting a sobering portrait of young people between the ages of 13 and 18 years. Even a cursory PSYCInfo search for adolescence and delinquency yields over 19,000 peer-reviewed articles. Adolescents' tumultuous reputation often leaves parents, educators, and community members concerned about their trajectories into adulthood. This picture of adolescence makes the positive youth development (PYD) approach critical to understanding the ways adolescents thrive in the context of major physical, cognitive, and emotional adjustment. As a framework, PYD takes an assets-focused perspective (Lerner et al., 2011), paying attention to the factors, relationships, and contexts promoting adolescent health, wellbeing, and achievement (Shek et al., 2019).

(c) $\mathbf{E Y}$ New articles in this journal are licensed under a Creative Commons Attribution 4.0 License. This journal is published by the University Library System, University of Pittsburgh and is cosponsored by the University of Pittsburgh Press. The Journal of Youth Development is the official peer-reviewed publication of the National Association of Extension 4-H Youth Development Professionals and the National AfterSchool Association. 
The Handbook of Positive Youth Development: Advancing Research, Policy, and Practice in Global Contexts (2021), edited by Radosveta Dimitrova and Nora Wiium, provides an expansive addition to the literature on PYD. It offers stakeholders across disciplinary boundaries cuttingedge frameworks and critical takeaways that will deeply inform research and practice efforts with adolescents. The 37 chapters that comprise this handbook are organized into two major sections: In the first, Positive Youth Development in Global Contexts, a nationally diverse group of scholars provides empirical evidence of PYD and related constructs in samples from around the world. This impressive collection of contributors lends their expertise to consider the validity and utility of PYD across national contexts, local settings, and ages, and towards various adaptive outcomes. Dimitrova and Wiium did well to prioritize construct invariance as a focal point of this section. As PYD was conceptualized and largely investigated in the United States, the attention to construct invariance is particularly critical for future research endeavors in other countries.

In the handbook's second section, Positive Youth Development Applications and Interventions, the focus shifts to the implications of the thoughtful research presented in Part 1. This collection of chapters suggests avenues for innovative and empirically sound youth interventions. The evidence-based insights in this section are especially relevant for practitioners who seek to create programming that promotes positive development in young people. Specific programs are described with findings that point to their effectiveness for disenfranchised youth in their respective locales. The Changing Lives Program in the United States (Eichas et al., Ch. 29, this volume), the Dream School Program in Norway (Larsen \& Holsen, Ch. 26, this volume), and Another Way Out in Canada (Miconi \& Rousseau, Ch. 28, this volume) are key examples of programs grounded in PYD. Another Way Out is especially pertinent, as young people the world over are facing the consequences of extreme xenophobic socialization.

A key strength of this handbook lies in the comprehensiveness of concepts covered in the chapters. The examination of the relationship between PYD and the reduction of risky behaviors (Uka et al., Ch. 10, this volume), concern for the environment (Kabir \& Wiium, Ch. 6, this volume), happiness (Gomez-Baya et al., Ch. 13, this volume), and leadership abilities (Bremner \& Schwartz, Ch. 21, this volume) demonstrate the value of this framework for understanding adolescence from a holistic perspective. Additionally, by considering the implications of PYD for academic achievement, this volume offers critical insight for educational researchers, practitioners, and policymakers concerned with the academic trajectories of youth around the world (see Kosic et al., Ch. 12 and Bradley et al., Ch. 15, this volume). Further, the systematic 
expansion of the Cs models in the first few chapters of the handbook is another significant contribution. Dimitrova and colleagues' addition of creativity to the previous 6 Cs model of PYD highlights a key, understudied adolescent resource. The three chapters (Ch. 2-4) dedicated to examining the invariance of the seven Cs model and its relationship to positive youth outcomes are a critical complement to existing research examining creativity as an asset.

The Handbook of Positive Youth Development has potential to influence the trajectory of ongoing research that disrupts the negative narratives of adolescence. The text's global perspective-research conducted using samples from an impressive 37 countries, across six continents-provides a foundation for ongoing collaborative efforts to examine PYD outside of Western, White, and middle-class populations, a critique of the psychological and developmental sciences (Dupree \& Kraus, 2021). Dimitrova and Wiium are intentional in having each chapter consider the specific ecologies of each research site, hence avoiding acontextual analyses and conclusions. This approach to the book is also reflected in the authorship of the chapters, where at least one author in most of the chapters represent an institution in the nations of interest. However, the same positionality is not reflected in those chapters with research conducted in majority Black national contexts. Future versions of this handbook should be consistent across all chapters, which may go far to provide an even more emic examination of the ways PYD may manifest across cultural settings. It can also be seen as a limitation that there are chapters focusing on developmental stages outside of adolescence, including early childhood and emerging adulthood. However, the continuity of youth development necessitates considering factors and strengths promoting positive youth development before and after adolescence.

The scope of topics covered by the chapters in Handbook of Positive Youth Development will make this a frequently cited resource for scholars, practitioners, and policy makers around the world. Dimitrova and Wiium should be commended for compiling this multidisciplinary text that considers PYD using multiple lenses. The handbook complicates our current understanding of PYD by questioning conventional theorizing and conceptualization and by directing readers to take a systems approach to the research. As Geldhof and colleagues write in the final chapter: "PYD-inspired practices can and must acknowledge contexts as both moderating youth development and a conduit through which youth development can be optimized" (Ch. 37, this volume). This text's intentionality in focusing across race/ethnicity, nationality, family, and school contexts will make it an important and engaging reference for those who are invested in adolescents' futures. 


\section{References}

Baumeister, R. F., Bratslavsky, E., Finkenauer, C., \& Vohs, K. D. (2001). Bad is stronger than good. Review of General Psychology, 5(4), 323-370. https://doi.org/10.1037/1089-2680.5.4.323

Bradley, G. L., Ferguson, S., \& Zimmer-Gembeck, M. J. (2021). Parental support, peer support and school connectedness as foundations for student engagement and academic achievement in Australian youth. In R. Dimitrova \& N. Wiium (Eds.), Handbook of positive youth development. Advancing research, policy and practice in global contexts (pp. 215-232). Springer.

Bremner, D., \& Schwartz, K. D. (2021). Leadership development of Zulu male youth in a South African township. In R. Dimitrova \& N. Wiium (Eds.), Handbook of positive youth development. Advancing research, policy and practice in global contexts (pp. 311-324). Springer.

Dimitrova, R., \& Wiium, N. (Eds.) (2021). Handbook of positive youth development: Advancing research, policy, and practice in global contexts. Springer.

Dupree, C. H., \& Kraus, M. W. (2021). Psychological science is not race neutral. Perspectives on Psychological Science, 1-6. https://doi.org/10.1177/1745691620979820

Eichas, K., Montgomery, M. J., Meca, A., Garcia, A. J., \& Garcia, A. (2021). Engaging marginalized youth in positive development: The Changing Lives Program. In R. Dimitrova \& N. Wiium (Eds.), Handbook of positive youth development. Advancing research, policy and practice in global contexts (pp. 427-442). Springer.

Geldhof, G. J., Olsen, S. J., \& Thogmartin, A. A. (2021). The morning sun shines brightly: Positive youth development in a global context. In R. Dimitrova \& N. Wiium (Eds.), Handbook of positive youth development. Advancing research, policy and practice in global contexts (pp. 563-574). Springer.

Gomez-Baya, D., de Matos, M. G., \& Wiium, N. (2021). Positive youth development and subjective happiness: examining the mediating role of gratitude and optimism in Spanish emerging adults. In R. Dimitrova \& N. Wiium (Eds.), Handbook of positive youth development. Advancing research, policy and practice in global contexts (pp. 183-198). Springer.

Kabir, R. S., \& Wiium, N. (2021). Positive youth development and environmental concerns among youth and emerging adults in Ghana. In R. Dimitrova \& N. Wiium (Eds.), Handbook of positive youth development. Advancing research, policy and practice in global contexts (pp. 81-94). Springer.

Kosic, M., Wiium, N., \& Dimitrova, R. (2021). Social support among Slovene minority and Italian majority youth in Italy: Links with positive identity, social competence and academic achievement. In $\mathrm{R}$. Dimitrova \& N. Wiium (Eds.), Handbook of positive youth development. Advancing research, policy and practice in global contexts (pp. 171-182). Springer.

Larsen, T. B., \& Holsen, I. (2021). Youth participation in the dream school program in Norway: An application of a logic model of the six Cs of positive youth development. In R. Dimitrova \& N. Wiium (Eds.), Handbook of positive youth development. Advancing research, policy and practice in global contexts (pp. 383-394). Springer. 
Lerner, R. M., Lerner, J. V., von Eye, A., Bowers, E. P., \& Lewin-Bizan, S. (2011). Individual and contextual bases of thriving in adolescence: A view of the issues. Journal of Adolescence, 34, 1107-1114. https://doi.org/10.1016/j.adolescence.2011.08.001

Miconi, D., \& Rousseau, C. (2021). Another Way Out: A Positive Youth Development Approach to the Study of Violent Radicalization in Québec, Canada. In R. Dimitrova \& N. Wiium (Eds.), Handbook of positive youth development. Advancing research, policy and practice in global contexts (pp. 411-426). Springer.

Paolini, S., \& McIntyre, K. (2019). Bad is stronger than good for stigmatized, but not admired outgroups: Meta-analytical tests of intergroup valence asymmetry in individual-to-group generalization experiments. Personality and Social Psychology Review, 23, 3-47. https://doi.org/10.1177/1088868317753504

Shek, D. T. L., Dou, D., Zhu, X., \& Chai, W. (2019). Positive youth development: Current perspectives. Adolescent Health, Medicine, and Therapeutics, 10, 131-141. https://doi.org/10.2147/AHMT.S179946

Uka, F., Bërxulli, D., Hasani, A., Peci, B., Taravari, B., \& Wiium, N. (2021). Developmental assets, academic achievement and risky behaviors among Albanians in Albania, Kosovo, Macedonia and Serbia. In R. Dimitrova \& N. Wiium (Eds.), Handbook of positive youth development. Advancing research, policy and practice in global contexts (pp. 133-150). Springer. 